\title{
The oily wastewater treatment using the nanofiltration process
}

\author{
${ }^{2}$ Aleksander Orecki, ${ }^{1}$ Maria Tomaszewska \\ Szczecin University of Technology, Institute of Chemical and Environmental Engineering, ul. Pułaskiego 10, 70-322 \\ Szczecin, Poland, \\ ${ }^{1}$ corresponding author: e-mail: maria.tomaszewska@ps.pl \\ ${ }^{2}$ corresponding author: e-mail: aleksander.orecki@biot.ar.szczecin.pl
}

\begin{abstract}
The objective of this work was to investigate the possibility of oily wastewater treatment using the nanofiltration (NF) process. The NF studies were carried out with a permeate obtained from ultrafiltration (UF) (used for the treatment of the oily wastewater from metal industry). The influence of transmembrane pressure on a permeate flux, the degree of the rejection of oil and inorganic compounds was investigated. The studies on the NF treatment of oily wastewater demonstrated a high effectiveness of the rejection of oil and inorganic compounds. The permeate obtained from the treatment was free of oil. Moreover, the retention coefficient of the inorganic compounds was higher than $75 \%$ for all the cations examined $\left(\mathrm{Na}^{+}, \mathrm{K}^{+}, \mathrm{Mg}^{2+}, \mathrm{Ca}^{2+}, \mathrm{Zn}^{2+}\right.$, $\mathrm{Cu}^{2+}$ ) and higher than $95 \%$ for sulphates. Therefore, the permeate obtained in the NF process can be reused for fresh emulsion preparation.
\end{abstract}

Keywords: nanofiltration, oily wastewater, inorganic compounds.

Presented at VII Conference Wasteless Technologies and Waste Management in Chemical Industry and Agriculture, Międzyzdroje, 12 - 15 June, 2007.

\section{INTRODUCTION}

Oily wastewater generated by various industries and discharged into the natural environment creates a major ecological problem throughout the world. Oily wastewater originating from cooling and lubricating emulsions from the metal industry contain a considerable amount of mineral oil, which hardly undergoes the biochemical decomposition. The traditional methods used for the separation of oily wastewater consist of a series of physical and chemical steps, namely: free oily removal, suspended solids removal, chemical emulsion break, dissolved air flotation, clarification and filtration ${ }^{1}$. The chemical methods are primarily based on the neutralization of detergents (emulsion's stabilizers), and a change of the $\mathrm{pH}$ solution ${ }^{2}$. The methods commonly used throughout the world for the treatment of oily wastewater can be categorized as the traditional: coalescence, coagulation, filtration, adsorption and modern methods based on the membrane technologies such as reverse osmosis, nanofiltration and ultrafiltration $^{3-7}$. Nanofiltration has found applications in a wide range of fields. With the separation characteristics between UF and RO, NF is used when the low molecular weight (MW) solutes have to be separated from the water. The separation mechanism of nanofiltration is normally explained in terms of charge and sieve effects. The sieving mechanism is responsible for the rejection of uncharged solutes by nanofiltration. Whereas, the rejection of the charged solutes by nanofiltration is also influenced by the electrostatic interaction between the solute species and the membrane surface, according to the Donnan exclusion phenomena ${ }^{8}$.

The objective of this work was to study the treatment of oily wastewater using the nanofiltration process as a second stage of treatment. In the NF process the majority of inorganic compounds and organic substances will be rejected. Therefore, the NF permeate regarding a high level of purification can be re-used in the technology. The influence of the transmembrane pressure on the permeate flux and the degree of retention of oil and inorganic com- pounds, with regard to oily wastewater, was investigated. In our previous investigations of the of bilge water treatment, we found that the ultrafiltration process could be used in the pre-treatment step?.

\section{EXPERIMENTAL}

The NF process was carried out in a pilot plant equipped with a tubular module with the AFC30 membrance (PCI) - the working area equal to $0.9 \mathrm{~m}^{2}$ ) and a spiral wound module (with the NF 270-2540 membrane (FilmTec - the working area equal to $2.6 \mathrm{~m}^{2}$ ). The studies earlier performed showed that the membranes differed in the molecular weight cut-off (MWCO). The MWCO of the studied membranes were equal to $180 \mathrm{~g} / \mathrm{mol}$ and $250 \mathrm{~g} / \mathrm{mol}$ for NF 270-2540 and NF AFC30, respectively. The scheme of the NF pilot plant is presented in Fig 1.

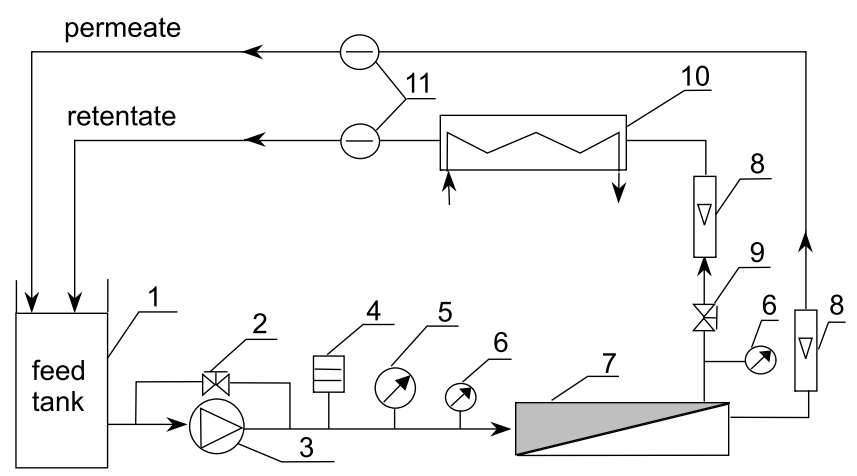

Figure 1. A scheme of the NF pilot plant; 1) feed tank; 2) by-pass valve; 3) pump; 4) dampener; 5) pressure gauge; 6) manometer; 7) NF module; 8) rotameter; 9) throttling valve; 10) heat exchanger; 11) control of the temperature and the conductivity

The process was operated in a closed system in which the permeate was recycled directly to the feed tank to ensure a constant feed concentration. The feeding was performed in a cross-flow system, where the feed flowed tangentially to the membrane. The investigations were 
carried out at constant transmembrane pressure equal to 1.0 MPa.

The feed comprised a permeate from the RO pilot plant (obtained from tap water) and the permeate obtained from the UF pretreatment of raw oily wastewater, respectively. The RO permeate was pure water, with the content of the TOC equal to $0.8 \mathrm{mg} / \mathrm{dm}^{3}$ and the electrical conductivity of $15 \mu \mathrm{S} / \mathrm{cm}$. Thus, the applications of the RO permeate as the feed allowed to determine the maximum permeate flux under given process conditions. The feed temperature was constant at the level of $25^{\circ} \mathrm{C}$. Samples of the permeate and the feed were collected every hour with the view to determining the concentration of oil (measured with the help of a Horiba OCMA-31), the total organic carbon (TOC) (measured with the use of a Multi N/C Analyzer - Analytic Jena) and the concentration of cations $\left(\mathrm{Na}^{+}\right.$, $\mathrm{K}^{+}, \mathrm{Mg}^{2+}, \mathrm{Ca}^{2+}, \mathrm{Zn}^{2+}, \mathrm{Cu}^{2+}$ ) (measured with the use ICPAES method using a Jobin Yvon Ultrace 238 JY spectrometer). The retention coefficient (R) was calculated using the following equation:

$\mathrm{R}=\left(1-\frac{\mathrm{C}_{\mathrm{P}}}{\mathrm{C}_{\mathrm{N}}}\right) * 100 \%$

where: $C_{P}$ - the concentration of the component in the permeate, $\mathrm{C}_{\mathrm{N}}$ - the concentration of the determined component in the feed.

\section{RESULTS AND DISCUSSION}

The raw oily wastewater used in the studies was collected from metal treatment industry. Apart from oil, the wastewater contained a lot of other contaminants, including solids state, lubricants, metal fines and sometimes dissolved metals. Iron and copper are the metals seen most often because equipment metallurgies are often fabricated from these metals. The raw oily wastewater demonstrated high turbidity, equal to 230 NTU and contained the suspended solid equal to $60 \mathrm{mg} / \mathrm{dm}^{3}$. Therefore, the ultrafiltration using the FP-100 membranes mounted in a tubular module was applied as the first step of the treatment of the spent liquor. The UF process was described earlier'. Although the UF membranes rejected oil in $90 \%$, the permeate still contained different solutes. The following parameters characterized the permeate UF: a high content of oil equal to 11,2 ppm and TOC value of 1380 $\mathrm{mg} / \mathrm{dm}^{3}$, the electrical conductivity was $2354 \mu \mathrm{S} / \mathrm{cm}$, TDS $2534 \mathrm{ppm}$. The studied wastewater also exhibited a high concentration of the $\mathrm{SO}_{4}{ }^{2-}$ ions $\left(509 \mathrm{mg} / \mathrm{dm}^{3}\right)$, very high concentration of the $\mathrm{Na}^{+}\left(1134 \mathrm{mg} / \mathrm{dm}^{3}\right)$ and $\mathrm{Cu}^{2+}(872$ $\left.\mathrm{mg} / \mathrm{dm}^{3}\right), \mathrm{K}^{+}\left(374 \mathrm{mg} / \mathrm{dm}^{3}\right)$. The concentration of other cations such as $\mathrm{Ca}^{2+}, \mathrm{Mg}^{2+}$ and $\mathrm{Zn}^{2+}$ did not exceed 10 $\mathrm{mg} / \mathrm{dm}^{3}$. The difference between the oil and the TOC concentration indicate that other, than the petroleum derivatives, organic compounds, are present in the studied waste. These compounds may also include the surface active agents, which are used for washing out the oil residues from the tanks used for waste storage.

The NF process has been used as a second stage of the oily wastewater treatment. The feed consisted of the permeate from the UF pretreatment of raw oily wastewater. The influence of the transmembrane pressure on the permeate flux is presented in Fig. 2.

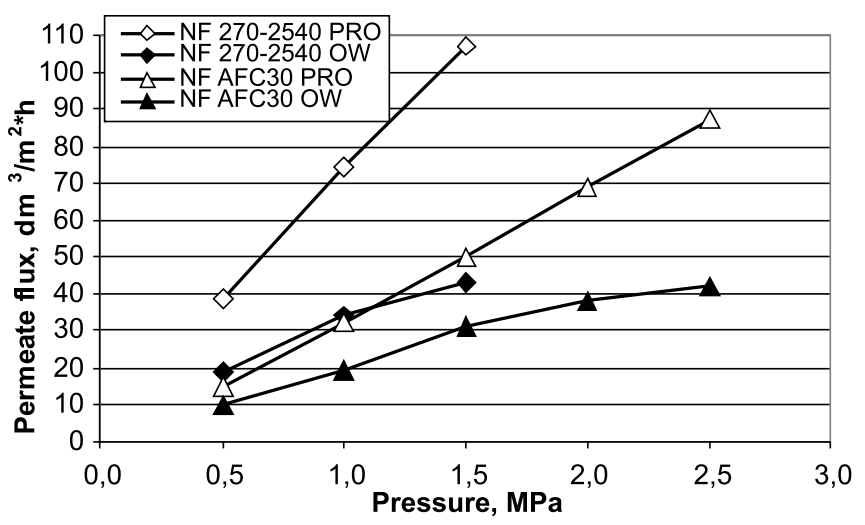

Figure 2. The influence of the transmembrane pressure on the permeate flux in the NF process for both studied membranes. The feed: the permeate obtained from the RO pilot plant (PRO), permeate obtained from the UF process of the raw oily wastewater $(\mathrm{OW})$

The maximum permeate flux (MPF) (signed as PRO) was determined using the permeate from the RO pilot plant as a feed. Since the RO permeate practically did not contain the organic substances, the membrane fouling did not occur. The linear increase of the permeate flux with an increase of the transmembrane pressure was observed (Fig. 2). However, during the NF of the UF permeate resultant from the raw oily wastewater treatment, the permeate flux was clearly lower. A flux decline was caused by the effect of the phenomena occurring in a layer adjacent to the membrane such as the concentration polarization and fouling. For the NF 270-2540 membrane, the permeate flux decreased by $50 \%$ in relation to the MPF (when the transmembrane pressure was equal to 1.0MPa). In the case of the NF AFC30 membrane, at the same transmembrane pressure, the permeate flux decreased by $10 \%$. However, the permeate flux obtained from the NF 270 - 2540 membrane was higher by about $15 \%$ $(\triangle \mathrm{P}=1.0 \mathrm{MPa})$ than that obtained from the NF AFC30 membrane. The difference was caused by the organic and inorganic compounds, present in the oily wastewater and the different construction of the studied modules. The spiral-wound module has the membrane spirally wounded with a distance spacer net that causes a high linear velocity of the feed and reduces the membrane blocking. On the other hand, the tubular module was constructed from a tube bundle with a diameter of $12.5 \mathrm{~mm}$, which causes a decrease of the linear velocity of the stream for the same feed flow rate and, hence a larger possibility of membrane pores blocking.

In the case of the NF process it was found that the transmembrane pressure did not influenced the degree of rejection of the studied pollution parameters. Therefore, the rejection degrees presented in Fig. 3 and Fig. 4 were achieved at the transmembrane pressure amounting to 1.0MPa.

The permeate obtained during the NF process for both membranes was free of oil. Thus the retention of oil equal to $100 \%$ was achieved independently of the used membranes. However, the rejection of the TOC was different for the membranes. The organic compounds (measured as TOC) were removed in $65 \%$ for NF $270-2540$ and $60 \%$ for NF AFC30. The differences between the rejections of 


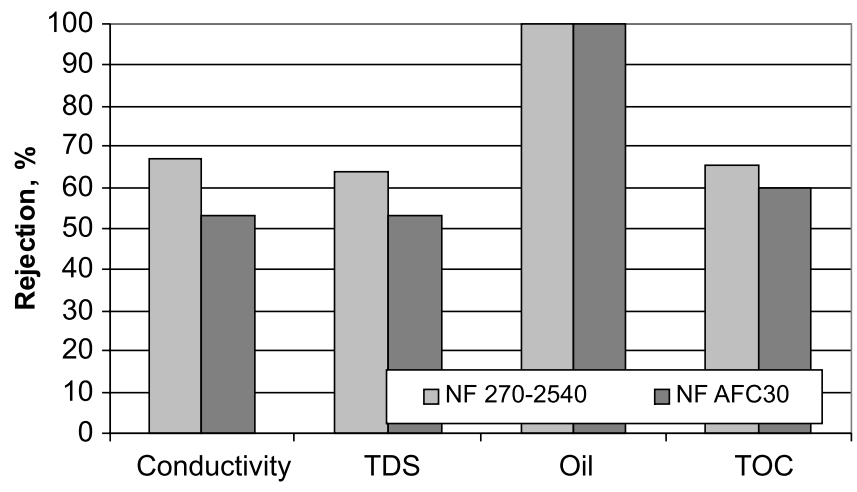

Figure 3. Rejection degrees of the TOC, oil and electrical conductivity for two NF membranes at a pressure of 1.0MPa. The feed: the UF permeate obtained when the raw oily wastewater was used as a feed

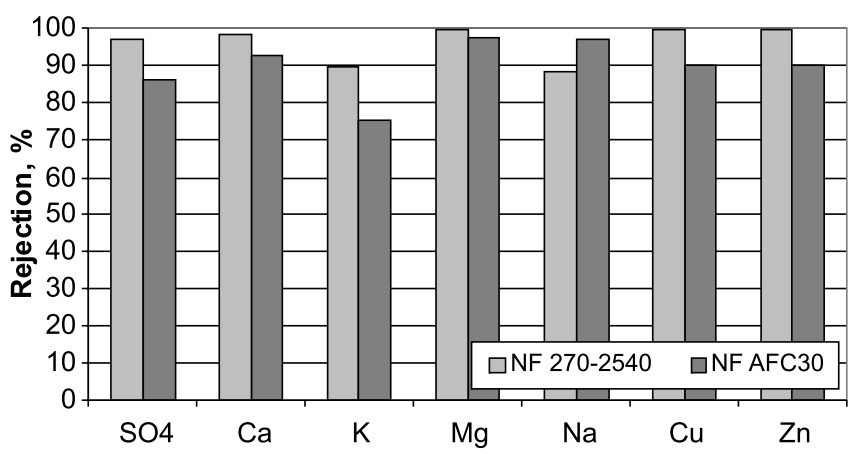

Figure 4. Rejection degrees of all the studied cations and sulphate for two NF membranes at a pressure of 1.0MPa. The feed: the UF permeate obtained when the raw oily wastewater was used as a feed

Table 1. A comparison of the effectiveness of both studied membranes $\left({ }^{*}-\right.$ limit detection)

\begin{tabular}{|l|c|c|c|c|}
\cline { 3 - 5 } \multicolumn{2}{c|}{} & \multicolumn{3}{c|}{ PERMEATE } \\
\cline { 3 - 5 } \multicolumn{2}{c|}{} & $\mu$ UF & NF 270-2540 & NF AFC30 \\
\hline Conductivity & $\mu S / c m$ & 2354 & 780 & 1100 \\
\hline TDS & $p p m$ & 2534 & 912 & $0^{*}$ \\
\hline Oil & $p p m$ & 11,2 & 476 & $0^{*}$ \\
\hline TOC & $m g / m^{3}$ & 1380 & 553 & \\
\hline
\end{tabular}

\begin{tabular}{|c|c|c|c|c|c|c|c|}
\hline & $\mathrm{SO}_{4}^{2-}$ & $\mathrm{Ca}^{2+}$ & $\mathrm{K}^{+}$ & $\mathrm{Mg}^{2+}$ & $\mathrm{Na}^{+}$ & $\mathrm{Cu}^{2+}$ & $\mathrm{Zn}^{2+}$ \\
\hline & \multicolumn{7}{|c|}{$m g / d^{3}$} \\
\hline Permeate UF & 508,98 & 5,42 & 373,65 & 8,41 & 1133,79 & 871,02 & 0,76 \\
\hline NF $270-2540$ & 14,82 & 0,07 & 37,61 & 0,04 & 135,82 & 3,647 & 0,005 \\
\hline NF AFC 30 & 70,02 & 0,41 & 91,34 & 0,21 & 33,08 & 83,715 & 0,073 \\
\hline
\end{tabular}

TOC for both membranes resulted from their different molecular weight cut-off. The values of concentrations achieved in two stages, combining the UF and the NF treatment of oily wastewater for both membranes are presented in Table 1. The rejection of all the studied inorganic compounds exceeded $75 \%$.

After accomplishing the studies carried out for $10 \mathrm{~h}$, a value of MPF was again determined. The obtained MPF was decreased by about $2-3 \%$ in relation to the initial value (for both studied membranes). The rinsing of the modules with the RO permeate, carried out for $1 \mathrm{~h}$ allowed the recovery of the transport properties of the membranes. It means that during the NF process of the UF permeate, subjected to a pre-treatment by the UF, the temporary fouling phenomenon took place.

The performed studies on the treatment of oily wastewater demonstrated that the NF process used as a second stage of treatment, showed high effectiveness. The application of the NF stage of the treatment allowed to achieve the permeate with the purity exceeding not only the standards concerning the discharge of oily wastewater into the environment but also offers a possibility to reuse the permeate as the process water in technology.

\section{CONCLUSIONS}

- As a result of the nanofiltration used as a second stage of oily wastewater treatment the removal of organic compounds (TOC) for the studied membranes (NF 270-2540 and NF AFC 30) exceeded 65\%. Moreover, the cations were rejected by $75 \%$ and the sulphates were rejected by $95 \%$. The permeate did not contain oil.

- The nanofiltration permeate regarding a high level of purification can be re-used in the technology.

\section{LITERATURE CITED}

(1) Hupka J., Miler J. D.: Environmental technology of oil pollution. The Second International Conference on Analysis and Utilization of Oily Wastes AUZO'99, August 29September 3, 1999, Gdańsk, Poland,.

(2) Gryta M., Karakulski K., Morawski A. W.: Purification of oily wastewater by hybrid UF/MD, Water Research, 2001, 35,3665 - 3669 .

(3) In-Soung, Chang-Mo, Seung-Ho Han, Treatment of oily wastewater by ultrafiltration and ozone, Desalination, 2001, 133, 225 - 232.

(4) Nordvik Atle B., Simmons James L., Bitting Kenneth R., Lewis Alun, Strom-Kristiansen Tove: Oil and Water Separation in Marine Oil Spill Clean-up Operations, Spill Science \& Technology Bulletin, 1996, 3 (3), 107 - 122.

(5) Betz M.: A Simple Way to Eliminate Oils from Water, Spill Science \& Technology Bulletin, 2002, 7 (5 - 6), 319 320.

(6) Curtis D.: Hydrocyclone for oil-from-water separation, Filtration \& Separation, 1996, 33 (4), 291 - 292.

(7) Hong A. G. Fane, Burford R.: The Effects of Permeate Flow on Membrane Coalescence of Oil-in-Water Emulsion, Membrane News, 2002, 60.

(8) Young Ku, Shi-Wei Chen, Wen-Yu Wang: Effect of solution composition on the removal of copper ions by nanofiltration, Sep. Purif. Techn., 2005, 43, 135 - 142.

(9) Tomaszewska M., Orecki A., Karakulski K.: Treatment of bilge water using combination of ultrafiltration and reverse osmosis, Desalination, 2005, 185, 1629 - 1638. 